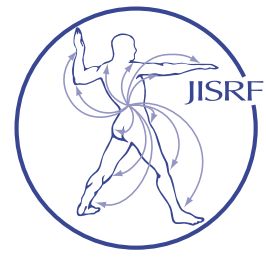

\title{
Decreased Incidence of Periprosthetic Joint Infection in Total Hip Arthroplasty with Use of Topical Vancomycin
}

Crawford $D^{1}$, Berend $K^{1}$, Adams J ${ }^{3}$, Lombardi $A^{2}$

\section{Abstract}

Background: Periprosthetic joint infections following total hip arthroplasty (THA) can cause significant patient morbidity and carry with them a substantial cost burden to the healthcare system. The purpose of this study was to assess whether the addition of topical vancomycin decreased the incidence of superficial and deep infections after primary total hip arthroplasty?

Methods: We performed a retrospective analysis of patients who underwent primary THA with (1070 hips) and without (815 hips) the use of topical vancomycin. Records were reviewed to determine incidence of PJI. Infections were categorized as deep or superficial. Medical comorbidity data was evaluated for known risk factors including diabetes, rheumatoid arthritis, and BMI. Records were further reviewed to determine surgical approach used and bacterial cause of PJI.

Results: The overall incidence of infection in the control group was $1.47 \%$ (12 hips) and significantly decreased to $0.47 \%$ (5 hips) with the addition of topical vancomy$\operatorname{cin}(\mathrm{p}=0.022)$. Deep infections also decreased from $0.86 \%$ (7 hips) in the control group to $0.09 \%$ (1 hip) in the vancomycin group $(\mathrm{p}=0.011)$. There was no difference in BMI or percent of patients with diabetes between groups. In all patients, regardless of vancomycin use, the incidence of infection in the direct lateral approach was higher $(2.04 \%, 9$ hips $)$ than the anterior approach $(0.055 \%, 8$ hips) $(\mathrm{p}=0.004)$.
Conclusions: We found a lower incidence of periprosthetic joint infection after THA with the addition of topical vancomycin. We also found a decreased incidence of infection in patients who had surgery through an anterior approach compared with those who had a direct lateral approach.

\section{Background}

Periprosthetic joint infections (PJI) remain one of the most devastating complications following total hip arthroplasty. Prevention of deep infection is paramount for reducing patient morbidity and health care cost associated with management of PJI as multiple surgeries, hospitalizations and outpatient antibiotics are often required to eradicate a deep infection. It is estimated that the incidence of PJI will be 40,000 to 80,000 per year in the United States by 2030 and have a cost burden of $\$ 2$ to 4 billion annually [1]. Management of a single PJI costs on average $\$ 50,000$ and can increase up to $\$ 100,000$ in cases with resistant organisms $[\underline{2}, \underline{3}]$.

Efforts to reduce infection begin preoperatively in optimizing patient factors. Obesity, malnutrition and poor dia-

Keywords: total hip, infection, vancomycin, antibiotic, arthroplasty

Level of Evidence: AAOS Therapeutic Level IV

Educational Value \& Significance: JISRF Level A 
betic control are all modifiable risk factors have all been shown to increase risk of infection [4-6] ]. Perioperative techniques to reduce risk of infection include proper surgical site prepping, perioperative antibiotics, use of laminar flow, decreasing surgical time and blood loss $[\underline{5}, \underline{7}, \underline{8}]$.

Local surgical site techniques to reduce risk of infection have also been employed. Some have advocated for copious irrigation with either antibiotic loaded solution or dilute betadine $[\underline{9}, \underline{10}]$. Topical antibiotics have been shown throughout the spine literature to significantly reduce surgical site infection [11-17]. Animal models have shown that the combination of local and systemic antibiotics significantly decrease the rate of wound infection compared to either modality alone [18].

Gram-positive bacteria are most commonly associated with PJI including staphylococcus aureus and staphylococcus epidermidis $[\underline{19}, \underline{20}]$. These bacteria adhere to implants and form a biofilm, which makes them difficult to treat [21]. Approximately $10 \%$ to $20 \%$ of infections are from gram-negative organisms and $20 \%$ of infections are polymicrobial $[\underline{22}, \underline{23}]$.

The purpose of this study was to assess whether the addition of topical vancomycin decreased the incidence of superficial and deep infections after primary total hip arthroplasty. Secondarily, we evaluated whether there was a difference in the incidence of infection between the direct lateral approach and the anterior supine intermuscular approach (ASI).

\section{Methods}

We performed a retrospective comparative cohort analysis of patients who underwent primary THA with and without the use of topical vancomycin. All patients signed a general research consent approved and monitored by our independent institutional review board (Western IRB; Puyallup, Washington) allowing retrospective research review. We separated patients by year in which they had surgery. In 2011, topical vancomycin was not used and this group served as the control. In 2015 all patients undergoing THA had $1 \mathrm{~g}$ of sterile vancomycin hydrochloride sprinkled in the wound after component implantation and prior to closure. The 2011 control group consisted of 746 patients $(815$ hips) while the 2015 intervention group had 987 patients (1070 hips). All surgeries in both groups were performed by one of three fellowship trained adult reconstruction surgeons using cementless femoral and acetabular components with polyethylene liners. Both groups of patients cleaned their surgical site preoperatively with chlorhexidine antiseptic skin cleanser, and DuraPrep ${ }^{\mathrm{TM}}$ Surgical So- lution (3M, St. Paul, Minnesota) was used intraoperatively for surgical preparation in both groups.

In 2011, patients had surgery performed at either an orthopaedic specialty hospital (639) or full service general hospital (176). In 2015, surgeries were performed at an orthopaedic specialty hospital (589), full service hospital (10) or outpatient surgery center (471).

Records were reviewed to determine incidence of PJI. Infections were categorized as deep or superficial based on a hip fluid cell count, culture and need for radical debridement. Medical comorbidity data was evaluated for known risk factors including diabetes, rheumatoid arthritis, and BMI. Records were further reviewed to determine surgical approach used and bacterial cause of PJI. Surgical approaches included a minimally invasive direct lateral approach and anterior supine intermuscular (ASI) or "anterior" approach.

\section{Statistical Analysis}

Chi-squared analysis was used to compare the incidence of infection with and without intrawound vancomycin as well as incidence of infection by approach. T-test was used to compare patients' height, weight and BMI between groups.

\section{Results}

Patient demographic information between the groups is listed on Table 1. Tables $2 \mathrm{a}$ and $2 \mathrm{~b}$ show differences in demographics and surgical data between approaches and year groups. In combining demographics between groups, the mean BMI in patients who had a direct lateral was $33 \mathrm{~kg} /$ $\mathrm{m} 2$ (range, 17.4 to 58.4), which was significantly higher than patients who had an ASI approach, BMI 30.46 (range, 12.2 to 62.02$) \mathrm{p}<0.001$. Operative time was significantly less in the 2015 vancomycin group both in patients who had an ASI approach $(\mathrm{p}<0.001)$ and direct lateral approach $(\mathrm{p}=0.02)$.

The overall incidence of infection in the control group was $1.47 \%$ (12 hips) and significantly decreased to $0.47 \%$ (5 hips) with the addition of topical vancomycin ( $\mathrm{p}=0.022$ ). Deep infections also decreased from $0.86 \%$ ( 7 hips) in the control group to $0.09 \%$ (1 hip) in the vancomycin group $(\mathrm{p}=0.011)$. Details of the infections that occurred are listed in Table $3 \mathrm{a}$ and $3 \mathrm{~b}$. The mean BMI of patients who developed an infection was $39.1 \mathrm{~kg} / \mathrm{m} 2$ (range, 26.6 to $58.2 \mathrm{~kg}$ / $\mathrm{m} 2)$. Five patients $(42 \%)$ in the control group who developed infections had diabetes mellitus, while three patients $(60 \%)$ in the vancomycin group who developed infections had rheumatoid arthritis. 
In comparing surgical approach, the 2011 control patients had their surgeries performed with a direct lateral in 314 hips (39\%) and ASI approach in 501 hips (61\%). There were 7 total infections $(2.23 \%)$ in the direct lateral group compared to 5 total infections (1.0\%) in the ASI group ( $\mathrm{p}=0.155)$. There were 5 deep infections $(1.59 \%)$ in the direct lateral group compared to 2 deep infections $(0.4 \%)$ in the ASI group ( $\mathrm{p}=0.072)$. Surgical approach in the 2015 vancomycin cohort was direct lateral in 126 hips (12\%) and ASI in 944 hips (88\%). There were 2 total infections (1.59\%) in the direct lateral group compared to 3 total infections $(0.32 \%)$ in the ASI group ( $\mathrm{p}=0.049)$. There was 1 deep infection $(0.79 \%)$ in the direct lateral group compared to 0 deep infections $(0 \%)$ in the ASI group $(\mathrm{p}=0.004)$.

Comparing the 2011 to 2015 direct lateral patients, the overall infection rates decreased from $2.23 \%$ to $1.59 \%$ with the addition of vancomycin but this was not statistically significant $(\mathrm{p}=0.667)$. The deep infection rate also decreased from $1.59 \%$ in the control group to $0.79 \%$ in the vancomycin group but was not significant $(\mathrm{p}=0.513)$. Comparing the 2011 to 2015 ASI patients, the overall infection incidence decreased from $1 \%$ to $0.32 \%$ but was not significant $(\mathrm{p}=0.097)$. The deep infection rate decreased from $0.4 \%$ to $0 \%(\mathrm{p}=0.024)$, which was significant.

In all patients, regardless of vancomycin use, the incidence of any infection in the direct lateral patients was $2.04 \%$ (9 hips) compared to $0.055 \%$ (8 hips) in the ASI approach $(\mathrm{p}=0.004)$. The incidence of deep infection in all direct lateral patients was $1.4 \%$ (6 hips) compared to $0.01 \%$ (1 hip) in the ASI approach ( $\mathrm{p}<0.001)$.

In 2011, five infections occurred in patients who had surgery at the general hospital and seven infections occurred in patients who had surgery at the specialty hospital. In 2015, four of the infections occurred in patients who had surgery at the specialty hospital and one infection occurred in a patient who had surgery at the outpatient surgery center. Each of the three surgeons performed surgery on at least four of the patients who developed infections in both groups combined.

\section{Discussion}

With the addition of topical vancomycin powder, we observed a significant reduction in overall and deep infections with only one deep infection in 1070 hips for incidence of $0.09 \%$. We further found that regardless of antibiotic use, the ASI surgical approach has a significantly lower frequency of any and deep infections than the direct lateral approach.
Table 1. Patient demographics compared between 2011 control group and 2015 vancomycin group

\begin{tabular}{|l|c|c|c|}
\hline Characteristic & $\mathbf{2 0 1 1}$ & $\mathbf{2 0 1 5}$ & P Value \\
\hline Gender (male:female) & $48 \%: 52 \%$ & $49 \%: 51 \%$ & 0.621 \\
\hline Age (years) & $63.3( \pm 11.9)$ & $64.8( \pm 10.2)$ & 0.004 \\
\hline Height (inches) & $67.0( \pm 4.3)$ & $67.5( \pm 4.3)$ & 0.035 \\
\hline Weight (pounds) & $199.8( \pm 51.9)$ & $201.6( \pm 52.0)$ & 0.472 \\
\hline BMI (kg/m2) & $31.1( \pm 7.3)$ & $31.0( \pm 7.0)$ & 0.828 \\
\hline Diabetes & $15.9 \%$ & $13.5 \%$ & 0.15 \\
\hline Rheumatoid arthritis & $2.6 \%$ & $6.3 \%$ & $<0.001$ \\
\hline
\end{tabular}

Table 2a. Patient demographics and operative differences compared between 2011 and 2015 THA performed with the anterior supine intermuscular (ASI) approach

\begin{tabular}{|l|c|c|c|}
\hline Characteristic & 2011 ASI & 2015 ASI & P Value \\
\hline Gender (male:female) & $47 \%: 53 \%$ & $48 \%: 52 \%$ & 0.724 \\
\hline Age (years) & $62.7( \pm 11.9)$ & $64.7( \pm 10.2)$ & 0.001 \\
\hline Height (inches) & $67.1( \pm 4.1)$ & $67.5( \pm 4.2)$ & 0.115 \\
\hline Weight (pounds) & $195.4( \pm 50.3)$ & $198.1( \pm 48.9)$ & 0.346 \\
\hline BMI (kg/m2) & $30.4( \pm 6.9)$ & $30.5( \pm 6.6)$ & 0.808 \\
\hline $\begin{array}{l}\text { Operative time } \\
(\text { minutes })\end{array}$ & $76.1( \pm 37.7)$ & $64.5( \pm 23.3)$ & $<0.001$ \\
\hline $\begin{array}{l}\text { Estimated blood loss } \\
(\mathrm{mL})\end{array}$ & $185.5( \pm 171)$ & $197.9( \pm 116)$ & 0.070 \\
\hline
\end{tabular}

Table 2b. Patient demographics and operative differences compared between 2011 and 2015 THA performed via the direct lateral approach

\begin{tabular}{|l|c|c|c|}
\hline Characteristic & 2011 Lateral & 2015 Lateral & P Value \\
\hline Gender (males:female) & $49 \%: 51 \%$ & $56 \%: 44 \%$ & 0.166 \\
\hline Age (years) & $64.1( \pm 11.9)$ & $64.9( \pm 10.8)$ & 0.512 \\
\hline Height (inches) & $67.0( \pm 4.7)$ & $67.7( \pm 5.0)$ & 0.163 \\
\hline Weight (pounds) & $206.8( \pm 53.9)$ & $227.8( \pm 65.7)$ & 0.001 \\
\hline BMI (kg/m2) & $32.2( \pm 7.9)$ & $34.9( \pm 9.1)$ & 0.003 \\
\hline $\begin{array}{l}\text { Operative time } \\
(\text { minutes })\end{array}$ & $72( \pm 29.4)$ & $64.3( \pm 23.3)$ & 0.020 \\
\hline $\begin{array}{l}\text { Estimated blood loss } \\
(\mathrm{mL})\end{array}$ & $182( \pm 145)$ & $158( \pm 116)$ & 0.200 \\
\hline
\end{tabular}

Buchholz et al first described the use of local antibiotics in 1970 [24] and since then the local application of antibiotic has been investigated in orthopedics, cardiothoracic, vascular, and spine surgeries [25-28]. Topical vancomycin use in spine surgery has shown a greater than $50 \%$ decrease in surgical site infections in spine surgery [29]. Johnson et al studied the local and serum vancomycin concentration levels after topical administration of vancomycin [30]. They evaluated 34 patients in whom $1 \mathrm{G}$ of vanco- 
Table 3a. Demographic and infection characteristics of 2011 control group patients who developed an infection.

\begin{tabular}{|c|c|c|c|c|c|c|}
\hline Gender & $\begin{array}{l}\text { Age } \\
\text { (years) }\end{array}$ & $\begin{array}{l}\text { BMI } \\
(\mathrm{kg} / \mathrm{m} 2)\end{array}$ & Diagnosis, Risk Factors & Approach & Infection & Organism(s) \\
\hline female & 40 & 37.2 & osteoarthritis, Larsen syndrome & anterior & deep & cultures negative \\
\hline female & 92 & 27.4 & osteoarthritis & anterior & deep & enterobacter cloacae, staphylococcus epidermidis \\
\hline female & 60 & 34.8 & osteoarthritis & anterior & superficial & $\begin{array}{l}\text { staphylococcus coagulase negative, } \\
\text { staphylococcus lugdenensis }\end{array}$ \\
\hline female & 80 & 36.1 & osteoarthritis, diabetes mellitus & anterior & superficial & gram negative rods, enterobacter cloacae \\
\hline female & 73 & 31.4 & osteoarthritis & anterior & superficial & $\begin{array}{l}\text { staphylococcus epidermidis (resistant), } \\
\text { propionibacterium acnes }\end{array}$ \\
\hline male & 57 & 45.4 & osteoarthritis, diabetes mellitus & lateral & deep & klebsiella pneumoniae, enterobacter cloacae \\
\hline female & 60 & 58.2 & osteoarthritis & lateral & deep & $\begin{array}{l}\text { staphylococcus aureus (methicillin resistant), rare } \\
\text { pseudomonas }\end{array}$ \\
\hline female & 66 & 46.2 & osteoarthritis, diabetes mellitus & lateral & deep & $\begin{array}{l}\text { staphylococcus epidermidis, escherichia coli, } \\
\text { staphylococcus warneri, acinetobacter }\end{array}$ \\
\hline female & 59 & 26.6 & developmental dysplasia & lateral & deep & group B beta streptococcus \\
\hline female & 71 & 42.6 & $\begin{array}{l}\text { osteoarthritis, history of } \\
\text { infection }\end{array}$ & lateral & deep & proteus mirabilis, escherichia coli, pseudomonas \\
\hline male & 60 & 37.6 & osteoarthritis, diabetes mellitus & lateral & superficial & staphylococcus aureus coagulase positive \\
\hline female & 42 & 56.6 & osteoarthritis, diabetes mellitus & lateral & superficial & gram negative rods, escherichia coli \\
\hline
\end{tabular}

Table 3b. Demographic and infection characteristics of 2015 vancomycin group patients who developed an infection.

\begin{tabular}{|l|l|l|l|l|l|l|}
\hline Gender & $\begin{array}{l}\text { Age } \\
(\mathbf{y e a r s})\end{array}$ & $\begin{array}{l}\text { BMI } \\
\mathbf{( k g / m 2})\end{array}$ & Diagnosis, Risk Factors & Approach & Infection & Organism(s) \\
\hline female & 62 & 27.5 & rheumatoid arthritis & anterior & superficial & staphylococcus aureus (methicillin resistant) \\
\hline female & 65 & 41.6 & $\begin{array}{l}\text { rheumatoid arthritis, history of } \\
\text { infection }\end{array}$ & anterior & superficial & pseudomonas aeruginosa \\
\hline female & 68 & 36.1 & $\begin{array}{l}\text { osteoarthritis, coronary artery } \\
\text { disease }\end{array}$ & anterior & superficial & pseudomonas aeruginosa \\
\hline female & 67 & 30.1 & $\begin{array}{l}\text { rheumatoid arthritis, coumadin } \\
\text { therapy }\end{array}$ & lateral & deep & coagulase negative staphylococcus \\
\hline female & 69 & 48.5 & osteoarthritis & lateral & superficial & $\begin{array}{l}\text { escherichia coli, proteus mirabilis, } \\
\text { peptostreptococcus anaerobius }\end{array}$ \\
\hline
\end{tabular}

mycin was mixed with $2 \mathrm{G}$ of tranexamic acid and injected into the drain tube after capsule closure. One gram of vancomycin was also sprinkled in the subcutaneous tissue. Intrawound and serum levels were measured at multiple time points up to 24 hours. They found the serum vancomycin levels remained on average below $5 \mu \mathrm{g} / \mathrm{mL}$ which is well below the normal serum therapeutic level of 10 to 20 $\mu \mathrm{g} / \mathrm{mL}$. Meanwhile, the wound concentration of vancomycin peaked on average at $922 \mu \mathrm{g} / \mathrm{mL}$. These findings support that topical vancomycin provides a highly therapeutic intrawound concentration, with low systemic absorption. Whiteside has described his technique of intra-operative irrigation of normal saline with vancomycin and polymyxin [17]. The wound is irrigated throughout the case with this solution as well as in the medullary canals prior to fi- nal implantation. In his reported series of 2293 arthroplasties, there were no cases of primary infection. There was one case of a deep infection that was attributed to an unrecognized hematoma that became infected.

There has been some concern about the potential for third body wear with the application of topical vancomycin. Qadir et al. performed a wear simulation study with 6 articulation stations, 3 of which had topical vancomycin and 3 without [31]. After 10 million cycles they found no difference in wear mark length, width or gravimetric wear between groups.

The direct anterior approach for total hip arthroplasty has gained popularity over the past decade with purported benefits of the muscle sparing nature, faster early recovery and ability to use fluoroscopic assistance for component 
placement and leg length assessment. While infection concern was not a driving factor behind our practice's transition to the anterior approach, we did find in this study a decreased incidence of overall and deep infections using the anterior approach compared to the direct lateral. In surgeons who perform both approaches, there may be some selection bias as the direct lateral (or alternate approach) may be chosen for patients who are more obese. This was shown in our current study in which the average BMI was significantly higher in patients who had their surgery done through a direct lateral approach. We also showed that as more THA were done through an anterior approach in 2015, the BMI of patients who had surgery via a direct lateral approach was significantly higher than patients in 2011 who had a direct lateral approach. Other studies have not shown a difference in risk of infection between anterior and other approaches. Ilchmann et al found no significant difference in the risk of infection in patients undergoing primary THA from either a direct anterior (2.3\%) or lateral transgluteal approach (1.7\%) [32]. Likewise, Malek et al did not find a significant difference in infection risk between the anterior or posterior approach [33]. With the differences in patient BMI between the two surgical approaches in our study, BMI itself may be more of a factor for risk of infection than the surgical approach.

This study has several limitations. The main limitation is the many variables that contribute to development of periprosthetic joint infections including medical comorbidities, obesity, nutritional status, surgical preparation, operative time, anemia, blood loss, and hospital arthroplasty volume $[\underline{2}, \underline{5}]$. We did find that the operative time was significantly less with either approach in the 2015 vancomycin group compared to the 2011 group. We did not however find a significant difference in blood loss between groups. We did not have data on preoperative hemoglo$\mathrm{bin} /$ hematocrit or postoperative transfusion rates. Preoperative and intraoperative surgical preparation was the same in both groups and thus should not be a confounding factor. All 3 locations where the surgeries were performed in both groups were high volume facilities. The surgical location did change somewhat between groups with the addition of an ambulatory surgery center in the 2015 group. Only one patient who had surgery at the ambulatory surgery center developed a superficial infection and no patients developed a deep infection. There is likely some selection bias on surgical location as patients with significant medical comorbidites were likely taken to the hospital for surgery. We did not assess patient nutritional status, which has been shown as risk factor for infection and is a limitation in our findings [34]. The BMI between the groups was pretty well matched and not significantly dif- ferent. Furthermore we did not find a difference in the incidence of diabetes between groups. The vancomycin group did have a significantly higher incidence of patients with rheumatoid arthritis and $60 \%$ of the patients who developed an infection in this group had rheumatoid arthritis. Even with the higher incidence of rheumatoid arthritis in the group, the incidence of overall and deep infections was lower. Other medical comorbidities, smoking status, and ASA class were not assessed, which limited our analysis of patient-related risk factors. Lastly was the limitation of the confounding finding of differences in the infection rates between the direct lateral approach and ASI approach as well as the increased usage of the ASI approach in the vancomycin group. We found significantly lower incidence of overall and deep infections in the ASI group regardless of vancomycin usage. The use of the ASI approach increased from $61 \%$ in 2011 to $88 \%$ in 2015 . This increased use of the ASI approach which we found had a lower infection rate is likely contributing to our findings of lower incidence of infection with addition of vancomycin in this group. We did however find that with the addition of vancomycin there was a significant decrease in the incidence of infection in patients who had their hip replacement from the ASI approach, but we did not find a difference in the direct lateral approach.

While this study does have several limitations in controlling for confounding variables, we did find a lower incidence of periprosthetic joint infection after THA with the addition of topical vancomycin. We also found a decreased incidence of infection in patients who had surgery through an ASI approach compared with those who had a direct lateral approach.

\section{References}

1. Bosco JA, Bookman J, Slover J, Edusei E, Levine B. Principles of antibiotic prophylaxis in total joint arthroplasty: current concepts. J Am Acad Orthop Surg. 2015 Aug;23(8):e27-35.

2. Kurtz SM, Lau E, Watson H, Schmier JK, Parvizi J. Economic burden of periprosthetic joint infection in the United States. J Arthroplasty. 2012 Sep;27(8 Suppl):61-5.e1.

3. Parvizi J, Pawasarat IM, Azzam KA, Joshi A, Hansen EN, Bozic KJ. Periprosthetic joint infection: the economic impact of methicillin-resistant infections. J Arthroplasty. 2010 Sep;25(6 Suppl):103-7.

4. George J, Klika AK, Navale SM, Newman JM, Barsoum WK, Higuera CA. Obesity epidemic: is its impact on total joint arthroplasty underestimated? an analysis of national trends. Clin Orthop Relat Res. 2017 Jul;475(7):1798-1806

5. Kong L, Cao J, Zhang Y, Ding W, Shen Y. Risk factors for periprosthetic joint infection following primary total hip or knee arthroplasty: a meta-analysis. Int Wound J. 2017 Jun; 14(3): 529-36

6. Walls JD, Abraham D, Nelson CL, Kamath AF, Elkassabany NM, Liu J. Hypoalbuminemia more than morbid obesity is an independent predictor of complications after total hip arthroplasty. J Arthroplasty. 2015 Dec;30(12):2290-5.

7. Kapadia BH, Jauregui JJ, Murray DP, Mont MA. Does preadmission cutaneous chlorhexidine preparation reduce surgical site infections after total hip arthroplasty? Clin Orthop Relat Res. 2016 Jul;474(7):1583-8.

8. Kim JL, Park JH, Han SB, Cho IY, Jang KM. Allogeneic blood transfusion is a significant risk factor for surgical-site infection following total hip and knee arthroplasty: a meta-analysis. J Arthroplasty. 2017 Jan;32(1):320-325. 
9. Brown NM, Cipriano CA, Moric M, Sporer SM, Della Valle CJ. Dilute betadine lavage before closure for the prevention of acute postoperative deep periprosthetic joint infection. J Arthroplasty. 2012 Jan;27(1):27-30.

10. Whiteside LA. Prophylactic peri-operative local antibiotic irrigation. Bone Joint J. 2016 Jan;98-B(1 Suppl A):23-6.

11. Bakhsheshian J, Dahdaleh NS, Lam SK, Savage JW, Smith ZA. The use of vancomycin powder in modern spine surgery: systematic review and meta-analysis of the clinical evidence. World Neurosurg. 2015 May;83(5):816-23.

12. Chiang HY, Herwaldt LA, Blevins AE, Cho E, Schweizer ML. Effectiveness of local vancomycin powder to decrease surgical site infections: a meta-analysis. Spine J. 2014 Mar 1;14(3):397-407.

13. Evaniew N, Khan M, Drew B, Peterson D, Bhandari M, Ghert M. Intrawound vancomycin to prevent infections after spine surgery: a systematic review and metaanalysis. Eur Spine J. 2015 Mar;24(3):533-42.

14. Ghobrial GM, Thakkar V, Andrews E, Lang M, Chitale A, Oppenlander ME, Maulucci CM, Sharan AD, Heller J, Harrop JS, Jallo J, Prasad S. Intraoperative vancomycin use in spinal surgery: single institution experience and microbial trends. Spine (Phila Pa 1976). 2014 Apr 1;39(7):550-5.

15. Khan NR, Thompson CJ, DeCuypere M, Angotti JM, Kalobwe E, Muhlbauer MS, Camillo FX, Klimo P Jr. A meta-analysis of spinal surgical site infection and vancomycin powder. J Neurosurg Spine. 2014 Dec;21(6):974-83.

16. Kang DG, Holekamp TF, Wagner SC, Lehman RA Jr. Intrasite vancomycin powder for the prevention of surgical site infection in spine surgery: a systematic literature review. Spine J. 2015 Apr 1;15(4):762-70.

17. Xiong L, Pan Q, Jin G, Xu Y, Hirche C. Topical intrawound application of vancomycin powder in addition to intravenous administration of antibiotics: A metaanalysis on the deep infection after spinal surgeries. Orthop Traumatol Surg Res. 2014 Nov;100(7):785-9.

18. Bergamini TM, Lamont PM, Cheadle WG, Polk HC Jr. Combined topical and systemic antibiotic prophylaxis in experimental wound infection. Am J Surg. 1984 Jun;147(6):753-6.

19. Aslam S, Darouiche RO. Prosthetic joint infections. Curr Infect Dis Rep. 2012 Oct;14(5):551-7.

20. Pandey R, Berendt AR, Athanasou NA. Histological and microbiological findings in non-infected and infected revision arthroplasty tissues. The OSIRIS Collaborative Study Group. Oxford Skeletal Infection Research and Intervention Service. Arch Orthop Trauma Surg. 2000;120(10):570-4.

21. Zimmerli W. Clinical presentation and treatment of orthopaedic implant-associated infection. J Intern Med. 2014 Aug;276(2):111-9.

22. Del Pozo JL, Patel R. Clinical practice. Infection associated with prosthetic joints. N Engl J Med. 2009 Aug 20;361(8):787-94.

23. Lamagni T. Epidemiology and burden of prosthetic joint infections. J Antimicrob Chemother. 2014 Sep;69 Suppl 1:i5-10.

24. Buchholz HW, Engelbrecht H. [Depot effects of various antibiotics mixed with Palacos resins]. Chirurg. 1970 Nov;41(11):511-5.

25. Bibbo C, Patel DV. The effect of demineralized bone matrix-calcium sulfate with vancomycin on calcaneal fracture healing and infection rates: a prospective study. Foot Ankle Int. $2006 \mathrm{Jul} ; 27(7): 487-93$.

26. Kanj WW, Flynn JM, Spiegel DA, Dormans JP, Baldwin KD. Vancomycin prophylaxis of surgical site infection in clean orthopedic surgery. Orthopedics. 2013 Feb;36(2):138-46.

27. Mohammed S, Pisimisis GT, Daram SP, Bechara CF, Barshes NR, Lin PH, Kougias P. Impact of intraoperative administration of local vancomycin on inguinal wound complications. J Vasc Surg. 2013 Apr;57(4):1079-83.

28. Vander Salm TJ, Okike ON, Pasque MK, Pezzella AT, Lew R, Traina V, Mathieu R. Reduction of sternal infection by application of topical vancomycin. J Thorac Cardiovasc Surg. 1989 Oct;98(4):618-22.

29. Devin CJ, Chotai S, McGirt MJ, Vaccaro AR, Youssef JA, Orndorff DG, Arnold PM, Frempong-Boadu AK, Lieberman IH, Branch C, Hedayat HS, Liu A, Wang JC, Isaacs RE, Radcliff KE, Patt JC, Archer KR. Intrawound vancomycin decreases the risk of surgical site infection after posterior spine surgery-a multicenter analysis. Spine $2018 \mathrm{Jan} ; 43(1)$ : 65-71

30. Johnson JD, Nessler JM, Horazdovsky RD, Vang S, Thomas AJ, Marston SB. Serum and wound vancomycin levels after intrawound administration in primary total joint arthroplasty. J Arthroplasty. 2017 Mar;32(3):924-28

31. Qadir R, Ochsner JL, Chimento GF, Meyer MS, Waddell B, Zavatsky JM. Establishing a role for vancomycin powder application for prosthetic joint infection prevention-results of a wear simulation study. J Arthroplasty. 2014 Jul;29(7):1449-56.

32. Ilchmann T, Zimmerli W, Bolliger L, Graber P, Clauss M. Risk of infection in primary, elective total hip arthroplasty with direct anterior approach or lateral transgluteal approach: a prospective cohort study of 1104 hips. BMC Musculoskelet Disord. 2016 Nov 14;17(1):471.
33. Malek IA, Royce G, Bhatti SU, Whittaker JP, Phillips SP, Wilson IR, Wootton JR, Starks I. A comparison between the direct anterior and posterior approaches for total hip arthroplasty: the role of an 'Enhanced Recovery' pathway. Bone Joint J 2016 Jun:98-B(6):754-60.

34. Bohl DD, Shen MR, Kayupov E, Della Valle CJ. Hypoalbuminemia independently predicts surgical site infection, pneumonia, length of stay, and readmission after total joint arthroplasty. J Arthroplasty. 2016 Jan;31(1):15-21.

\section{SUBMISSION HISTORY}

Submitted March 01, 2018

Reviewed March 7, 2018

Accepted March 12, 2018

Published September 30, 2018

AUTHOR AFFILIATIONS

1 David A Crawford, MD; Keith R Berend, MD Joint Implant Surgeons, Inc, New Albany, OH, USA; and Mount Carmel Health System, New Albany, OH, USA

2 Adolph V Lombardi, MD, FACS

Joint Implant Surgeons, Inc, New Albany, OH, USA; The Ohio State University Wexner Medical Center, Columbus, OH, USA; and Mount Carmel Health System, New Albany, OH, USA

3 Joanne B Adams, BFA Joint Implant Surgeons, Inc, New Albany, OH, USA

Direct inquires to:

David A Crawford

Joint Implant Surgeons, Inc.

7277 Smith's Mill Road, Suite 200

New Albany, Ohio 43054 United States

Phone: 1 (614) 221-6331

Fax: 1 (614) 220-0393

Email: crawfordda@joint-surgeons.com

\section{AUTHOR DISCLOSURES}

The institution of one or more of the authors (DAC, KRB, JBA, AVL) has received funding from Zimmer Biomet, Inc (Warsaw, IN, USA), Pacira Pharmaceuticals Inc (Parsippany, NJ, USA), and SPR Therapeutics (Cleveland, OH, USA). One of the authors (AVL) lists the following relevant financial activities, during the study period, outside of this work and/or any other relationships or activities that readers could perceive to have influenced, or that give the appearance of potentially influencing, this manuscript: an amount of more than USD 1,000,001 from Zimmer Biomet (royalties, consulting fees), an amount of USD 10,000 to USD 100,000 from Innomed (royalties; Savannah, GA, USA), an amount of less than USD 10,000 from Pacira Pharmaceuticals (consulting fees), an amount of less than USD 10,000 from Orthosensor (consulting fees, royalties; Dania Beach, FL, USA), and an amount of USD 100,000 to USD 1,000,000 in SPR Therapeutics (equity interest). One of the authors certifies that he (KRB) has or may receive payments or benefits, during the study period, an amount of more than USD 1,000,001 from Zimmer Biomet (consulting fees, royalties), and an amount of USD 100,000 to USD 1,000,000 in SPR Therapeutics (equity interest).

Ethical Board Review statement: Each author certifies that his or her institution approved the human protocol for this investigation and that all investigations were conducted in conformity with ethical principles of research.

Work performed at: Joint Implant Surgeons, Inc., New Albany, Ohio

\section{COPYRIGHT \& OPEN ACCESS}

(C) 2018 Crawford, Berend, Adams, Lombardi. All rights reserved. Authors retain copyright and grant the journal right of first publication with the work. Reconstructive Review is an open access publication and follows the Creative Commons Attribution-NonCommercial CC BY-NC. This license allows anyone to download works, build upon the material, and share them with others for non-commercial purposes as long as they credit the senior author, Reconstructive Review, and the Joint Implant Surgery \& Research Foundation (JISRF). An example credit would be: "Courtesy of (senior author's name), Reconstructive Review, JISRF, Chagrin Falls, Ohio". 